\title{
An Unusual Case of Acute Pancreatitis in a Child
}

\author{
Joshi BG' ${ }^{1}$ Wadhwa ${ }^{2}$ \\ ${ }^{1}$ Dr. Binita G Joshi, MBBS, MD, ${ }^{2}$ Dr. Nishant Wadhwa, MBBS DCH DNB MNAMS. From the Institute of Child Health, Sir \\ Ganga Ram Hospital, New Delhi, India.
}

Address for correspondence: Dr. Binita G Joshi, E-mail: binitasay@yahoo.com

\begin{abstract}
Ascaris lumbricoides is a common intestinal parasite in tropical regions.Pancreatitis due to worm infestation is an uncommon but important cause in this region. While there are reports of pancreatic duct invasion by round worms in adults, such cases are rarely reported in pediatric population. We report one such case in a sixteen year old child.
\end{abstract}

Key words: Ascaris Lumbricoides, Pancreatitis, ERCP.

\section{Introduction}

$P$ ancreatitis due to Ascaris lumbricoides infestation develops as a result of passage of worm into the pancreatic duct or bile duct through the sphincter of Oddi. Impaction of roundworm into the pancreatic duct is extremely rare due to the duct's narrowness ${ }^{1,2}$. We report a case of Ascaris induced pancreatitis in a sixteen year old child, diagnosed by sonography and confirmed and removed endoscopically.

\section{The Case}

A sixteeen year old previously healthy boy presented with a three day history of fever, severe abdominal pain and persistent vomiting. On physical examination he was dehydrated, had low grade fever and generalized abdominal tenderness with guarding.

Laboratory test results showed leukocytosis of $16 \times 10^{9} / \mathrm{L}$ with $79 \%$ neutrophils. The serum amylase level was 2538U/L, lipase: 1533U/L, aspartate aminotransferase: $61 \mathrm{U} / \mathrm{L}$, alanine aminotransferase: $11 \mathrm{U} / \mathrm{L}$, alkaline phosphatase level: 312U/L, gamma glutamyl transferase level $42 \mathrm{U} / \mathrm{L}$ and the total bilirubin was $0.7 \mathrm{mg} / \mathrm{dl}$. The abdominal ultrasonography revealed echogenicity and dilatation in pancreatic duct suggestive of a linear foreign body in the main pancreatic duct. An endoscopy performed using side viewing scope showed one worm projecting out of an ampulla and another worm seen distally in the small intestine. An adult worm was extracted through the endoscope channel using a snare (Fig.1).The patient was also treated with albendazole and his subsequent recovery was uneventful.He was discharged 72 hours after the initial admission.

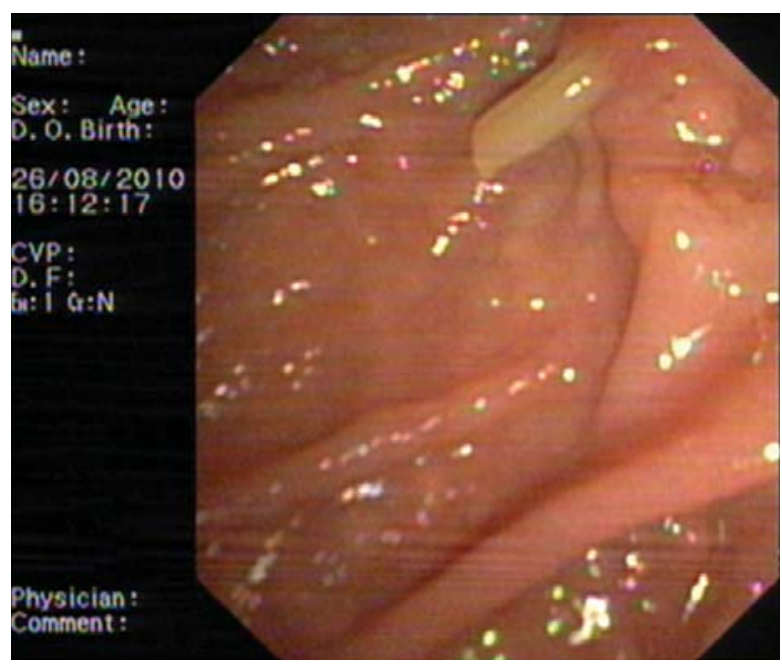

Fig.1 : Endoscopic view showing adult round worm projecting from the pancreatic duct.

\section{Discussion}

The adult roundworm, Ascaris lumbricoides is the most common helminthic infestation of human gastrointestinal tract and is estimated to affect more than 1.3 billion people worldwide with the majority of infections occurring in the developing countries of Asia and Latin America. The worm flourishes in the areas where poor sanitation and contaminated food and water exits ${ }^{3}$. Ampulla is frequently invaded by adult worm as it is located in upper small intestine. Adult worms migrate to common bile duct, intrahepatic duct, gall bladder or less commonly to pancreatic duct leading to biliary colic, cholangitis or pancreatitis ${ }^{4}$. A large study done in India by Khuroo et al showed that hepato-pancreatic ascariasis as an etiological factor for acute pancreatitis was $23 \%$ out of which $2.3 \%$ were due to worm in the 
pancreatic duct. Treatment by ERCP was successful in $95 \%$ of those cases $^{5}$. Similar study done by Sandouk et al reported pancreatitis due to pancreatic duct invasion by ascaris is $1.4 \%{ }^{6}$.

Ultrasonography is a safe and noninvasive tool for the diagnosis of hepatobiliary and pancreatic complication.It also determines the anatomic position of the worms, their motility and number and the status of the intra and extra hepatic biliary system. The worms usually appear as linear echogenic structures without acoustic shadowing ${ }^{7}$. ERCP has both diagnostic and therapeutic role in biliary and pancreatic ascariasis. However, removal of ascaris from the pancreatic duct may be difficult because of the lack of space in the duct. In our case, we used the snare to grasp the worm and succeeded in several attempts. Literatures have shown that there is a rapid improvement in signs and symptoms in pancreatic ascariasis after the endoscopic removal of worm, as in this case ${ }^{8}$. Though the previous literatures stated that pancreatic ascariasis respond well to conservative treatment, the newer studies have shown that the medical treatment along with ERCP for the management helps prevent complications of pancreatic ascariasis ${ }^{9}$. Patients usually have worms in gastrointestinal tract also; therefore an antihelminthic regimen should accompany the endoscopic procedure 3 .

\section{References}

1. Leung JWC, Mok SD, Metreweli C. Ascaris-Induced Pancreatitis. AJR 1987;149:511-12.
2. Yoo KS, Song HG, Kim KO, et al. Acute pancreatitis due to impaction of Ascaris lumbricoides in the Pancreatic Duct. Case Report. Pancreas 2007;35(3):290-2.

3. Mackrell PJ, Lee Kristin, Garcia N, et al. Pancreatitis secondary to Ascaris lumbricoides Infestation. Surgery 2001;129:511-2.

4. Grover SB, Pati N, Rattan SK. Sonographic Diagnosis of Ascaris InducedCholecystitis and Pancreatitis in a Child. J Clin Ultrasound 2001;29(4)254-59.

5. Khuroo MS, Zargen SA, Koul P, et al. Ascaris induced acute pancreatitis. Br J Surg 1992;79:1335-38.

6. Sandouk F, Haffer S, Zada MM, et al. Pancreaticbiliary ascariasis; experience of 300 cases. Am J Gastroenterol 1997;92;2264-7.

7. Bahu MG, Baldisseroto $M$, Custodio $C M$, et al. Hepatobiliary and Pancreatic Complications of Ascariasis in Children: A study of Seven Cases. J Pediatr Gastroenterol Nutr 2001; 33:271-5.

8. Misra SP, Dwivedi M. Endoscopy-assisted emergency treatment of gastroduodenal and pancreatobiliary ascariasis. Endoscopy 1996;28;629-32.

9. Darlong LM, Das Rubul, Hajong R, Topno N. A report of two cases of ascariasis managed conservatively. Ann Trop Med Public Health 2011;4:48-50.

\section{How to cite this article?}

Joshi BG, Wadhwa N. An Unusual Case of Acute Pancreatitis in a Child. J Nepal Paediatr Soc 2012;32(1):69-70. 